\title{
Self-reported Use of Complementary and Alternative Medicine among Moroccan Women with Breast Cancer
}

\author{
Bouchra Haddou Rahou ${ }^{1,2, *}$, Karima EI Rhazi ${ }^{3}$, Zaki Hanchi $^{4}$, Fatima Ouasmani ${ }^{1,2}$, Bouchra Benazzouz ${ }^{1}$, \\ Abdelhalem Mesfioui ${ }^{1}$ \\ ${ }^{1}$ Laboratory of Genetic, Neuroendocrinology and Biotechnology, Faculty of Sciences, University of Ibn Tofail, Morocco \\ ${ }^{2}$ High Institute of Nursing Professions and Technical Health, Rabat, Morocco \\ ${ }^{3}$ Department of Epidemiology and Public Health, Faculty of Medicine and Pharmacy of Fez, \\ Sidi Mohamed Ben Abdillah University, Morocco \\ ${ }^{4}$ National Institute of Oncology, Rabat, Morocco
}

Copyright $\bigcirc 2017$ by authors, all rights reserved. Authors agree that this article remains permanently open access under the terms of the Creative Commons Attribution License 4.0 International License

\begin{abstract}
The objective of this study was to assess the prevalence, types, sociodemographic and clinical-related factors of complementary and alternative medicine use among Moroccan women with breast cancer. A cross-sectional study was carried out at the National Institute of Oncology in Rabat. 400 patients with breast cancer were recruited for face-to-face interviews. Data were collected using a questionnaire addressing personal $/$ medical characteristics and the use of CAM therapies. $88.5 \%$ of women used at least one CAM therapy, $73.2 \%$ of them reported began to use CAM at the onset of breast cancer symptoms. Type of CAM commonly used were prayers, listening and/or reading the Koran and use of naturel products like honey or fenugreek. High education level was independent factors related to CAM use. Interventions should be focused on open communication and further researches are needed to explore the safety and the outcome of CAM use.
\end{abstract}

Keywords Complementary and Alternative Medicine, Breast Cancer, Morocco

\section{Introduction}

Breast cancer is by far the most frequent women cancer in the world [1]. In Morocco, it is the leading cancer among women and its incidence has increased steadily for reach 39.9 new cases per 100,000 women [2].

In spite of major attributes of early detection and treatment, studies have shown that breast cancer and its treatment processes affect the quality of life of patients [3, 4]. Therefore, many cancer patients seek complementary and alternative therapies [5.6].

According to the National Centre for Complementary and
Alternative Medicine (NCCAM), complementary and alternative medicine (CAM) is defined as "a group of diverse medical and health care systems, practices, and products that are not presently considered to be part of conventional medicine" [7].

Nearly half of all cancer patients report CAM use [5] and studies suggest higher rates among women with breast cancer [8] with a prevalence varying between $20 \%$ and $98 \%$. [9-11].

Younger age, higher socio-economic status, adjuvant therapy and higher education level have been shown associated with the rate of CAM use [12-16].

There are specific cancer-related reasons for using CAM. Wells et al. and Boon et al. [17, 18] noted that CAM therapies are often used for symptom management. Other studies, showed that many breast cancer patients have turned to CAM with hope of increasing the body's ability to fight the disease $[19,20]$ and improving physical and/or emotional wellbeing [20,21]. It have been demonstrated also that the kind of the CAM therapy used is linked to the patient's county, culture and religion [22].

The Middle East and North Africa region (MENA) harbors are one of the fastest growing markets of CAM products in the world [23-26]. In Morocco, CAM use is rooted in historical and traditional medicine and its use is increasing in cancer patients, However little is known about the use of CAM therapies among breast cancer patients in Morocco. The present study aimed to assess the prevalence, types and socio-demographic and clinical-related factors of CAM use among Moroccan women with breast cancer.

\section{Materials and Methods}

It was a cross-sectional quantitative study. The sample consisted of 400 patients with breast cancer recruited for face-to-face interviews consecutively. All patients were 
recruited as outpatients at the gynecological and breast cancers unit of National Institute of Oncology in Rabat from June 2014 to June 2015. This gynecological and breast cancers unit is the first and the main Moroccan's cancer referring center, receiving patients from all parts of the country.

We're being able to attend interviews, Moroccan female breast cancer patients with a pathological first diagnosis of primary breast cancer and who were under treatment. Patients who had a known history of psychiatric disorder or dementia were excluded from the study.

Data were collected using a questionnaire addressing personal/medical characteristics and the use of CAM therapies. Information on socio-demographic variables was collected during the face-to-face interviews while the clinical variables were obtained from patients' medical records.

CAM user was defined as an individual who had used one or more of the reported types of CAM. Categories of CAM were defined according to the National Center for Complementary and Alternative Medicine guidelines [7]. Thus, CAM practices are grouped into broad categories, such as natural products, mind and body medicine and manipulative and body-based practices. Natural Products includes use of a variety of herbal medicines, vitamins, minerals, and other "natural products". Mind and body practices focus on the interactions among the brain, mind, body, and behavior, with the intent to use the mind to affect physical functioning and promote health. Manipulative and body-based practices focus primarily on the structures and systems of the body, including the bones and joints, soft tissues, and circulatory and lymphatic systems.

The collected data were coded, entered and analyzed using the statistical package SPSS version 18.0. Descriptive statistics were used for the description of socio-demographic and clinical variables. All groups of quantitative data were verified using the Kolmogorov-Smirnov test in order to evaluate their distribution. Distributions were tabulated for the numbers of each major CAM category and specific CAM therapy to assess which CAM therapies were most frequently used. The logistic regression model was used to explore the associated factors of CAM use. The variables selected for this model were those with a trend $(\mathrm{P}<0.25)$ or a statistically significant association $(\mathrm{P}<0.05)$ with $\mathrm{CAM}$ use based on univariate analyses.

The ethical committee of medical and pharmacy school of Rabat approved the study protocol. Before the interview survey, the interviewer explained the purpose of the questions to all eligible women and requested their participation. All participants signed an informed consent form prior to being interviewed. All assessments were based on private interviews conducted all by researcher.

\section{Results}

A total of 400 breast cancer participated in the study. The mean age of this sample was 48.17years old (range 24-79, SD 10.24), majority were married (61\%), illiterate $(65 \%)$ and housewives $(86,2 \%)$. Regarding the clinical data, more than half of patients were in stage II breast cancer (58.8\%). The Mean time since diagnosis was 7.28 months $(\mathrm{SD} \pm 3.73$ ). Patient demographics are outlined in Table 1.

Out of the 400 patients surveyed, 354 (88.5\%) reported using CAM therapy. $15.8 \%$ of them used CAM as alternative medicine (table 2).

More than two-thirds of CAM users $(73.2 \%)$ reported began to use CAM at the onset of breast cancer symptoms, $21.2 \%$ of them prior to the diagnosis and before the beginning of treatment and only $5.6 \%$ began to use CAM during treatment (table 3)

The use of CAM was divided into three categories naturel products, mind and body medicine and the third category is manipulative and body-based practices. The most common used forms were mind body medicine $(89.8 \%)$ and naturel products $(83.9 \%)$ (Figure1). The various types of CAM used by the study population are illustrated in table 4 .

Among the mind body medicine reported were prayers, listening and/or reading the Koran, Hajj to the Holy Land of Mecca, visiting mausoleums and traditional healers. Most commonly used were prayers $(87 \%)$ and listening and/or reading the Koran (83.1\%).

Mausoleum ("Siyyed") is the grave of a very religious person, according to the beliefs of the visitors. Patients visit it and then pray/make duas so that the person (for whom the mausoleum was built) can be a mediator between God and them. Patients can also light candles or bind pieces of their clothes to the trees with a wish to cure.

Patients may consult traditional healer. A person who uses long-established methods passed down from one healer to another to treat a person suffering from various illnesses. He offers a number of treatments and practice traditional systems of medicine, which involves use of a variety of herbs and minerals. Amulets (hjab), containing verses from the Koran written by traditional healers and are usually worn around the neck. Traditional healer may also be consulted to give cure through "roukia" by reciting religious texts.

Among naturel products used were honey, Zamzam water (water brought from mecca), royal jelly, euphorbia honey (Daghmous), camel milk, aristo lochia, linen, nigella, fenugreek, turmeric and ginger. The most used were honey $(52.3 \%)$ and fenugreek (48.9\%).

Used as a nutritional source in daily life and medicine, Royal Jelly, which the queen honeybee requires for its development, is mainly secreted by the mandibular and hypopharyngeal glands of worker honeybees (Apis mellifera).

The euphorbia is plant that exists in its natural state mainly in the Middle Atlas and the high atlas of morocco and whose honey (Daghmous) is prized for its therapeutic virtues.

Aristolochia longa L. (Aristolochiaceae) locally known as "Barraztam" is a plant species communally used in Moroccan traditional medicine especially in cancer. 
Nigella sativa Linn, is commonly known by Moroccan people as black seed or Sanouj. Traditionally, there is a common Islamic belief that the 'black seed' is a panacea (universal healer).

Seeds of linen, turmeric, ginger and fenugreek .are using for medicinal purposes either alone or mixed with honey

Common Manipulative and body-based practices reported were cauterizing with fire, cupping, sand bath, thermal cure and bee venom acupuncture. Cauterizing with fire was the most used (16.9\%) followed by cupping (10.7\%).

Cauterizing with fire (Al-Kayy) is a method of treatment of disease in the time of Prophet (s.a.w), al-kayy or hot metal was used as a way to burn a wound to stop the blood or stop it becoming infected.

Cupping called Hijjama is another methode using a jar or a similar material.A jar is attached to the skin surface, so that the dirty blood, air, toxic and other harmful substance flow to the surface of the skin. Then, harmful substance may remove from the body

Practiced in Saharan regions of Morocco in particular Merzouga and M'hamid El Ghizlane, the Sand bath is practical immersion in burning sand during the summer when the temperatures are very high. The hot sand (70 to $80^{\circ} \mathrm{C}$ ) absorbs excess moisture content in the whole body, especially the bones.

Patients in our study reported visiting the hydrothermal complex of Moulay Yacoub, who is located in the north center of Morocco. Its warm waters are the most important and most visited of Morocco, for their therapeutic virtues such us mineralization, temperature and flows.

Bee venom acupuncture (BVA) involves injecting purified and diluted bee venom into acupoints. The bee venom once extracted and processed is utilized on the relevant sites according to specific diseases

Results of univariate analysis revealed that patients who were celibate (OR: 2.484, $\mathrm{p}=0.010, \mathrm{CI}$ : [1.246, 4.955]), high educated (OR: 5.198, p < 0.0001, CI: [2.556, 10.569]) and living in urban area (OR: 3.005, $\mathrm{p}=0.015, \mathrm{CI}$ : [1.238, 7.297]), appeared to engage in CAM use more than those who were illiterate, married and patients living in rural. In multivariate analyses, only high education level was independent factors related to CAM use (OR: $3.348, \mathrm{p}=$ 0.004, CI: [1.478, 7.584]) (Table 5).

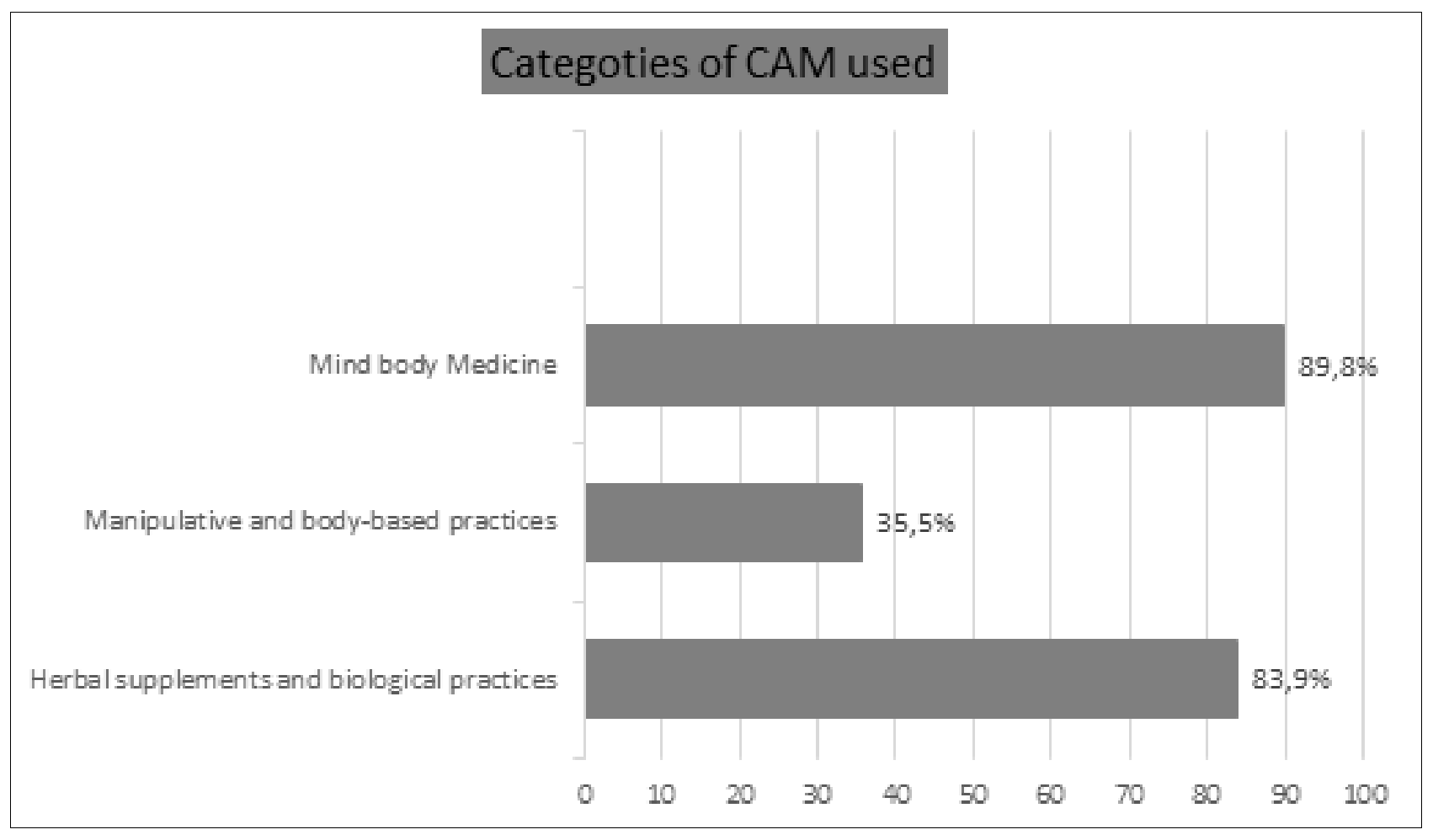

Figure 1. Categories of CAM use 
Table 1. Socio - demographic and clinical characteristics of study population $(n=400)$

\begin{tabular}{|c|c|c|}
\hline Variables & Effective & $\%$ \\
\hline \multicolumn{3}{|l|}{ Demographic characteristics } \\
\hline Age Mean (SD) & $\begin{array}{l}48.17 \text { years (Range: } 24-79) \\
S D=10.24\end{array}$ & \\
\hline \multicolumn{3}{|l|}{ Residence } \\
\hline Urban & 284 & 71 \\
\hline Rural & 116 & 29 \\
\hline \multicolumn{3}{|l|}{ Marital status } \\
\hline Celibate & 70 & 17.5 \\
\hline Married & 244 & 61 \\
\hline Divorced & 26 & 6.5 \\
\hline Widowed & 60 & 15 \\
\hline \multicolumn{3}{|l|}{ Educational level } \\
\hline Illiterate & 260 & 65 \\
\hline Primary level & 65 & 16.25 \\
\hline Secondary level & 46 & 11.5 \\
\hline University level & 29 & 7.25 \\
\hline \multicolumn{3}{|l|}{ Occupation } \\
\hline Housewife & 345 & 86.25 \\
\hline Active & 44 & 11 \\
\hline Retired & 3 & 0.75 \\
\hline Student & 8 & 2 \\
\hline \multicolumn{3}{|l|}{ Social security } \\
\hline No & 4 & 1 \\
\hline Yes & 396 & 99 \\
\hline \multicolumn{3}{|l|}{ Type of social security (n=396) } \\
\hline AMO Insurance ${ }^{1}$ & 53 & 14.2 \\
\hline RAMED Insurance $^{2}$ & 343 & 85.8 \\
\hline \multicolumn{3}{|l|}{ Clinical characteristics } \\
\hline $\begin{array}{l}\text { Time since diagnostic (months) } \\
\text { Mean (SD) }\end{array}$ & $\begin{array}{l}\text { 7.28(Range: } 1-17) \\
\mathrm{SD}=3.73\end{array}$ & \\
\hline \multicolumn{3}{|l|}{ Stage } \\
\hline I -II & 257 & 64.25 \\
\hline III - IV & 143 & 35.75 \\
\hline \multicolumn{3}{|l|}{ Current Treatment } \\
\hline Surgery & 133 & 33.25 \\
\hline Chemotherapy & 124 & 31.0 \\
\hline Radiotherapy & 143 & 35.75 \\
\hline \multicolumn{3}{|l|}{ Menopause } \\
\hline Yes & 233 & 58.25 \\
\hline No & 167 & 41.75 \\
\hline \multicolumn{3}{|l|}{ Family history of breast cancer } \\
\hline Yes & 180 & 45.0 \\
\hline No & 220 & 55.0 \\
\hline
\end{tabular}


Table 2. Prevalence of CAM use

\begin{tabular}{llll}
\hline \multicolumn{1}{c}{ CAM use } & Effective & \% \\
\hline Yes & 354 & 88.5 & \\
No & 46 & 11.5 \\
Alternative use $(\mathrm{n}=354)$ & 56 & 15.8 \\
Complementary use $(\mathrm{n}=354)$ & 298 & 84.2 \\
\hline
\end{tabular}

Table 3. The beginning of CAM use $(n=354)$

\begin{tabular}{lll}
\hline Time period & Effective & \% \\
\hline At the onset of symptoms & 259 & 73.2 \\
After diagnosis before treatment & 75 & 21.2 \\
During treatment & 20 & 5.6 \\
\hline
\end{tabular}

Table 4. Type of CAM used $(n=354)$

\begin{tabular}{|c|c|c|}
\hline Type of CAM used & Effective & $\%$ \\
\hline \multicolumn{3}{|l|}{ Natural products } \\
\hline Honey & 185 & 52.3 \\
\hline Zamzam /holy Water ${ }^{1}$ & 124 & 35.0 \\
\hline Royal jelly & 32 & 9.0 \\
\hline Euphorbia honey & 125 & 35.3 \\
\hline Camel milk & 58 & 16.4 \\
\hline Aristo lochia & 53 & 15.0 \\
\hline Linen & 74 & 20.9 \\
\hline Nigella & 152 & 42.9 \\
\hline Fenugreek & 173 & 48.9 \\
\hline Turmeric (curcuma) & 116 & 32.8 \\
\hline Ginger & 53 & 15.0 \\
\hline \multicolumn{3}{|l|}{ Mind and body Medicine } \\
\hline Prayers & 308 & 87.0 \\
\hline Listening and/or reading the Koran & 294 & 83.1 \\
\hline Hajj to the Holy Land & 19 & 5.4 \\
\hline Visiting mausoleums & 107 & 30.2 \\
\hline Traditional healers & 110 & 31.1 \\
\hline \multicolumn{3}{|l|}{ Manipulative and body-based practices } \\
\hline Cauterizing with fire ${ }^{2}$ & 60 & 16.9 \\
\hline Cupping & 38 & 10.7 \\
\hline Sand bath & 7 & 2 \\
\hline Thermal cure & 1 & 0.3 \\
\hline Bee venom acupuncture & 28 & 7.9 \\
\hline
\end{tabular}

${ }^{1}$ Type of holy water for Muslims, brought from Mecca

${ }^{2}$ Cauterization is a term describing the burning of part of a body to remove or close off a part of it in a process called cautery, which destroys some tissue 
Table 5. Logistic regression CAM use and socio-demographic and clinical characteristics

\begin{tabular}{|c|c|c|c|c|c|c|c|c|}
\hline \multirow[t]{2}{*}{ Characteristic } & \multirow{2}{*}{$\begin{array}{c}\text { CAM users }(\mathrm{n}=\mathbf{3 5 4}) \\
\mathbf{n}(\%)\end{array}$} & \multirow{2}{*}{$\begin{array}{c}\begin{array}{c}\text { CAM } \\
\text { nonusers } \\
(n=46)\end{array} \\
n(\%)\end{array}$} & \multicolumn{3}{|c|}{ Univariate analysis } & \multicolumn{3}{|c|}{ Multiyariate analysis } \\
\hline & & & OR & P-Value & $95 \% \mathrm{CI}$ & OR & P-Value & $95 \% \mathrm{CI}$ \\
\hline \multicolumn{9}{|l|}{ Age } \\
\hline$>50$ years & $214(86.6)$ & $33(13.4)$ & & & & & & \\
\hline$\leq 50$ years & $140(91.5)$ & $13(8.5)$ & 0.602 & 0.142 & {$[0.306,1.84]$} & 0.961 & 0.981 & {$[0.54,2.048]$} \\
\hline \multicolumn{9}{|l|}{ Residence area } \\
\hline Rural & $110(94.8)$ & $6(5.2)$ & & & & & & \\
\hline Urban & $244(85.9)$ & $40(14.1)$ & 3.005 & 0.015 & {$[1.238,7.297]$} & 1.763 & 0.256 & {$[0.662,4.691]$} \\
\hline \multicolumn{9}{|l|}{ Educational level } \\
\hline Illiterate & $243(93.5)$ & $17(6.5)$ & & & & & & \\
\hline Primary level & $56(86.2)$ & $9(13.8)$ & 2.297 & 0.058 & {$[0.973,5.428]$} & 1.807 & 0.216 & {$[0.708,4.613]$} \\
\hline Secondary and high level & $55(73.3)$ & $20(26.7)$ & 5.198 & 0.000 & {$[2.556,10.569]$} & 3.348 & 0.004 & {$[1.478,7.584]$} \\
\hline \multicolumn{9}{|l|}{ Marital status } \\
\hline Married & $218(89.3)$ & $26(10.7)$ & & & & & & \\
\hline Divorced and Widowed & $82(95.3)$ & $4(4.7)$ & 0.4 .9 & 0.106 & {$[0.139,1.208]$} & 0.429 & 0.135 & {$[0.141,1.300]$} \\
\hline Celibate & $54(77.1)$ & $16(22.9)$ & 2.484 & 0.010 & {$[1.246,4.955]$} & 1.578 & 0.227 & {$[0.752,3.318]$} \\
\hline \multicolumn{9}{|l|}{ Occupation } \\
\hline Unemployed & $316(88.8)$ & $40(11.2)$ & & & & & & \\
\hline Employed & $38(86.4)$ & $6(13.6)$ & 1.247 & 0.638 & {$[0.496,3.135]$} & & & \\
\hline \multicolumn{9}{|l|}{ Stage } \\
\hline I-II & $227(88.3)$ & $30(11.7)$ & & & & & & \\
\hline III-IV & $127(88.8)$ & $16(11.2)$ & 0.953 & 0.884 & {$[0.500,1.816]$} & & & \\
\hline \multicolumn{9}{|c|}{ Family history of breast cancer } \\
\hline No & $197(89.5)$ & $23(10.5)$ & & & & & & \\
\hline Yes & $157(87.2)$ & $23(12.8)$ & 1.255 & 0.469 & {$[0.679,2.320]$} & & & \\
\hline
\end{tabular}




\section{Discussion}

In this cross-sectional study, 400 breast cancer patients were surveyed about their use of CAM. Our survey showed that the majority of women with breast cancer had used CAM and many patients began to use CAM at the onset of disease symptoms. Prayer and Quran were the most CAMs commonly used followed by Honey, whereas manipulative and body-based practices are less used. We found that CAM use was strongly associated with education level.

The prevalence of CAM use among the study participants was $88.5 \%$. This prevalence is close to that recorded in Korea (74.8\%) [27] yet it is much higher than reported in more than 11 countries of Europe (44.7\%) [20]. Nevertheless, a comparison of the observed prevalence of CAM between studies is difficult because study population and definition of CAM may differ across studies [28, 29]. In addition, the variations in prevalence could be explained by differences in socio-cultural perceptions of CAM use and disparities in the availability and access to conventional medicine, [30]. The high prevalence of CAM use in our study could be attributed to Moroccan culture that encourages the use of complementary therapies specially plants and spiritual healing. On the other hand, an increased need for more personalized health and a greater public access to health information (i.e., the Internet) and popular media attention to CAM fuel its increasing use in Morocco.

Most women diagnosed with breast cancer in this study (73.2 \%) had begun to use CAM therapies before diagnosis (at the onset of symptoms). which is in contrast with other findings who reported that CAM use increases significantly following cancer diagnosis [31] or once medical therapy begins [32]. This may be explaining by differences in values, culture and perception of CAM use. Indeed a study about knowledge, perceptions and attitudes towards cancer in Morocco conducted by Lalla Salma Fondation [33], stated that there is a strong belief in traditional medicine as means of cancer therapy and $67 \%$ of study participants consider that the high cost of modern medicine pushes patients to traditional medicine.

Furthermore, this study reported an alarming finding that $15.8 \%$ of patients stopped medical treatment for a period to use CAM. It is a serious problem which should be further exploited and for which immediate interventions are needed.

In line with other research on CAM use by cancer patients $[34,35]$, the finding of our study showed that the mind body therapies was the most CAM used, followed by natural products. By contrast, manipulative and body-based practices were less likely to be used. The specific therapies selected within the two most used categories were prayer, Listening and/or reading the Koran, honey and Fenugreek.

The high degree of spirituality in CAM user patients in our study is in accordance with studies who revealed that women with breast cancer have earlier shown high spirituality and religious coping [36, 37]. In addition, Montazeri et al reported that spiritual healing was the most popular CAM modality used by almost $80 \%$ of cancer patients [35]. Hence, with regard to Morocco as a predominantly religious-spiritual society, this frequency is not surprising. Patients believe that illness is a divine test and the curer is God.

Moreover, the prevalent use of honey (52.3\%) may be related to his healing powers, which are reported in the Koran [38]. As well, the use of Fenugreek by $48.9 \%$ of CAM might be due to the common belief that such therapies are natural and nontoxic, even though such a belief is not scientifically supported. Many cancer patients believed that CAM could boost the immune system, reduce pain, relieve stress, prevent cancer recurrence and cope with side effects of conventional treatment [39].

It is important to highlight that $15 \%$ of patients in the present study used Aristo lochia that is a very toxic and irritating plant. It is a carcinogen and teratogen and could cause serious eye diseases, respiratory and digestive tracts irritation [23]. Brahmi et al [24] have revealed this finding in 2011 by demonstrating that $21 \%$ of Moroccan cancer patients used this dangerous plant. Therefore, special attention should be given to communication about this plant and these adverse effects.

Among manipulative and body-based practices, the cauterizing with fire and Cupping were the most used. This may be related to Muslim religion patients, which encourages their use. On the other hand, recently the great media coverage of new methods like Bee venom acupuncture increases their use by breast cancer patients in Morocco.

Our finding showed no difference between CAM users and non-users regarding age, residence area, marital status and stage of disease. Nevertheless, the association of education with CAM use is in line with findings of multiple investigators who reported that lower level of education associated with less use of CAM therapies [32, 40, 41]. This finding may be related to the fact that women with high education level can be better informed about health issues, including awareness of CAM therapies.

Meanwhile, there is evidence to support some of the CAM approaches, particularly in the symptom management and supportive care of cancer patients [42]. More and more medical centers now develop programs that integrate conventional medicine with complementary approaches that have some high-quality scientific evidence of safety and effectiveness [43].

\section{Limitations}

The current study provided important information about prevalence, types and factors associated to CAM use among Moroccan women with breast cancer. However, Interpretation of data must consider some limitations like sample size and study design. The cross-sectional design allowed identification of factor associated with CAM use, although causal inferences could not be made. 


\section{Conclusions}

Findings of our study indicated that Moroccan women with breast cancer use CAM widely. High-educated patients were at risk to use CAM than those illiterate. The type of CAM commonly used was prayers, listening and/or reading the Koran and use of naturel products like honey or fenugreek. Health-care professionals need to be educated about the most common CAM therapies used by breast cancer patients. Open communication regarding CAM use will help patients and clinicians to have safe and holistic care.

The findings of this study should be the target of further research, emphasizing the need for interventional studies that explore safe and effective CAM approaches who can be integrated with conventional treatment in breast cancer care in Morocco.

\section{Acknowledgements}

We thank: All women with breast cancer who agreed to voluntarily participate in this research, Staff of the National Oncology Institute of Rabat for their warm collaboration and Lalla Salma foundation "Prevention and treatment of cancers" for the continued support which is granted to the scientific research.

\section{REFERENCES}

[1] Ferlay J, Soerjomataram I, Ervik M, Dikshit R, Eser S, Mathers C, Rebelo M, Parkin DM, Forman D, Bray, F. Cancer incidence and mortality worldwide: Sources, methods and major patterns in GLOBOCAN 2012 .Int. J. Cancer. 2015; 136: $359-386$

[2] Benider A, Harif M, Karkouri M, Quessar A, Sahraoui S, Sqalli S. Cancer registry of Casablanca region, years 2005, 2006,2007. 2012; pp 59-62.

[3] Montazeri A. Health-related quality of life in breast cancer patients: A bibliographic review of the literature from 1974 to 2007. Journal of Experimental \& Clinical Cancer Research. 2008; 27: 32

[4] Haddou Rahou B, El Rhazi K, Ouasmani F, Nejjari C, Bekkali R, Montazeri A, Mesfioui A. Quality of life in Arab women with breast cancer: a review of the literature. Health and Quality of Life Outcomes. 2016; 14: 64

[5] DiGianni LM, Garber J, Winer EP. Complementary and alternative medicine use among women with breast cancer. J Clin Oncol 2002; 20: 34S-48S.

[6] McDermott CL, Blough DK, Fedorenko CR et al. Complementary and alternative medicine use among newly diagnosed prostate cancer patients. Support Care Cancer 2010; 20: 65-73.

[7] National Center for Complementary and Alternative Medicine (NCCAM). What Is Complementary and
Alternative Medicine?, 2008. Updated May 2012, Available https://nccih.nih.gov/sites/nccam.nih.gov/files/D347_05-252012.pdf

[8] Astin J. A, Reilly C, Perkins C, Child W. L. Breast cancer patients' perspectives on and use of complementary and alternative medicine: a study by the Susan G. Komen Breast Cancer Foundation. Journal of the Society for Integrative Oncology. 2006; 4: 157-169.

[9] Buettner C, Kroenke CH, Phillips RS, Davis RB, Eisenberg DM, Holmes MD. Correlates of use of different types of complementary and alternative medicine by breast cancer survivors in the nurses' health study. Breast Cancer Res Treat. 2006; 100:219-27.

[10] Gray RE, Fitch M, Goel V, Franssen E, Labrecque M. Utilization of complementary/alternative services by women with breast cancer. J Health Soc Policy 2003; 16:75-84.

[11] Cui Y, Shu XO, Gao Y, Wen W, Ruan ZX, Jin F, et al. Use of complementary and alternative medicine by Chinese women with breast cancer. Breast Cancer Res Treat. 2004; 85:26370 .

[12] Boon H., Stewart $M$ and Kennard M.A. The use of complementary/ alternative medicine by breast cancer survivors in Ontario: Prevalence and perceptions. Journal of Clinical Oncology. 2000; 18: 2515-2521.

[13] Akyol A.D. and Oz B. The use of complementary and alternative medicine by patients with cancer: in Turkey. Complementary Therapies in Clinical Practice.2011; 17: 230-4.

[14] Burstein H.J, Gelber S, Guadagnoli E, Weeks J. Use of alternative medicine by women with early-stage breast cancer. New England Journal of Medicine. 1999; 340: 1733-1739.

[15] Richardson M.A, Sanders T, Palmer J.L. Complementary/alternative medicine use in a comprehensive cancer center and the implications for oncology. Journal of Clinical Oncology. 2000; 18: 2505-2514.

[16] Rees R.W, Feigel I and Vickers A. Prevalence of complementary therapy use by women with breast cancer: a population -based study. European Journal of Cancer. 2000; 36: $1359-1364$

[17] Wells M, Sarna L, Cooley M, Brown J, Chernecky C, Williams $\mathrm{R}$ et al. Use of complementary and alternative medicine therapies to control symptoms in women living with lung cancer. Cancer Nursing. 2007; 30: 45-55.

[18] Boon H, Olatunde F, Zick, S M. Trends in complementary/ alternative medicine use by breast cancer survivors: Comparing survey data from 1998 and 2005 .BMC Women's Health. 2007; 7:4.

[19] Chen Z, Gu K, Zheng Y. The use of complementary and alternative medicine among Chinese women with breast cancer. Journal of Alternative and Complementary Medicine. 2008; 14: 1049-5.

[20] Molassiotis A, Scott J A, Kearney N. Complementary and alternative medicine use in breast cancer patients in Europe. Supportive Care in Cancer. 2006; 14: 260-267.

[21] Lengacher CA, Bennett M P, Kip K E. Relief of symptoms, side effects and psychological distress through use of complementary and alternative medicine in women with 
breast cancer. Oncol Nurs Forum. 2006; 33: 97-4.

[22] Von Gruenigen VE, White L J, Kitven M, Showalter A L, Hopkins M P, Jenison EL. A comparison of complementary and alternative medicine use by gynecology and gynecologic oncology patients. International Journal of Gynecological Cancer. 2001; 11: 205-209.

[23] Hamamouchi M. Les plantes médicinales et aromatiques marocaines. Édition 1999; p 389.

[24] Brahmi S A, El M'rabet F Z, Benbrahim Z, Akesbi Y, Berraho A, Nejjari C, El Mesbahi O. Complementary medicine use among Moroccan patients with cancer: A descriptive study. Pan African Medical Journal. 2011; 10:36.

[25] Tazi I, Nafil H, Mahmal L, Harif M, Khouchani M, Saadi Z, Belbaraka R, Elomrani A, Tahri A. Complementary medicine in cancer patients under treatment in Marrakech, Morocco: a prospective study. Bull. Soc. Pathol. Exot. 2013; 106:278-285

[26] Nutraceuticals Market: Middle East and North Africa (MENA) Industry Analysis and Opportunity Assessment, 2015 - 2020. In: Syndicated research. Future Market Insights 2015.http://www.futuremarketinsights.com/reports/details/m ena-nutraceuticals-market. Accessed 06 October 2016.

[27] Ock S M, Choi J Y, Cha Y S, et al. The use of complementary and alternative medicine in a general population in South Korea: results from a national survey in 2006. Journal of Korean Medical Science. 2009; 24: 1-6.

[28] Ernst E, Cassileth BR. The prevalence of complementary/ alternative medicine in cancer: a systematic review. Cancer. 1998; 83:777-782

[29] Kristoffersen AE, Fonnebo V, Norheim AJ. Use of complementary and alternative medicine among patients: classification criteria determine level of use. J Altern Complement Med. 1998; 14:911-919.

[30] Chang HY, Wallis M, Tiralongo E. Use of complementary and alternative medicine among people living with diabetes: literature review. J Adv Nurs. 2007; 58:307-19.

[31] Algier L A, Hanoglu Z, Ozden G, Kara F. The use of complementary and alternative (non-conventional) medicine in cancer patients in Turkey. European Journal of Oncology Nursing. 2005; 9: 138-146.

[32] Ashikaga T, Bosompra K, O’Brien P, Nelson L. Use of complementary and alternative medicine by breast cancer patients: Prevalence, patterns and communication with physicians. Supportive Care in Cancer. 2002; 10: 542-548.

[33] Lalla Salma Fondation, National plan for prevention and control of cancer, Axe demographics perception and needs, Available in: http://www.contrelecancer.ma/fr/documents/

[34] Gansler T, Kaw C, Crammer C, Smith T. A population based study of prevalence of complementary methods use by cancer survivors: a report from the American Cancer Society's studies of cancer survivors. Cancer. 2008; 113:1048-1057.

[35] Montazeri A, Sajadian A, Ebrahimi M, Haghighat S, Harirchi I. Factors predicting the use of complementary and alternative therapies among cancer patients in Iran. Eur J. Cancer Care (Engl). 2007; 16: 144-9.

[36] Wildes KA, Miller AR, de Majors SS, Ramirez AG. The religiosity/spirituality of Latina breast cancer survivors and influence on health-related quality of life. Psychooncology. 2009 ; 18:831-40.

[37] Ursaru M, Crumpei I, Crumpei G. Quality of life and religious coping in women with breast cancer. Procedia Soc Behav Sci. 2013; 114:322-6.

[38] Karadeniz C, Pinarli FG, Oğuz A, et al. Complementary/ alternative medicine use in a pediatric oncology unit in Turkey. Pediatr Blood Cancer. 2007; 48:540-3.

[39] Gulluoglu B M, Cingi A, Cakir T, Barlas A. Patients in northwestern Turkey prefers herbs as complementary medicine after breast cancer diagnosis. Breast Cancer. 2008; 3: 269-3.

[40] Eschiti V S. A model of CAM use by women with female specific cancers. Journal of Psychosocial Nursing. 2008; 46: 50-57.

[41] Lee M M, Lin S S, Wrensch M R, Adler S R, Eisenberg D. Alternative therapies used by women with breast cancer in four ethnic populations. Journal of the National Cancer Institute. 2000; 92: 42-47.

[42] Ernst E. The role of complementary and alternative medicine in cancer. Lancet Oncol. 2000; 1:176-180.

[43] Cassileth BR, Vickers AJ. High prevalence of complementary and alternative medicine use among cancer patients: implications for research and clinical care. J Clin Oncol 2005; 23:2590-2592. 